Article

\title{
Experiential Learning through Role-Playing: Enhancing Stakeholder Collaboration in Water Safety Plans
}

\author{
Giuliana Ferrero $^{1, *(D)}$, Françoise Bichai ${ }^{1,2}$ and Maria Rusca ${ }^{3}$ \\ 1 IHE Delft Institute for Water Education, 2611 AX Delft, The Netherlands \\ 2 École Polytechnique de Montréal, P.O. Box 6079, Downtown Station, Montreal, QC H3C 3A7, Canada; \\ fbichai@polymtl.ca \\ 3 King's College London, Department of Geography, The Strand, London WC2R 2LS, UK; \\ maria.rusca@kcl.ac.uk \\ * Correspondence: g.ferrero@un-ihe.org; Tel.: +31-15-21-51-773
}

Received: 13 December 2017; Accepted: 15 February 2018; Published: 23 February 2018

\begin{abstract}
Improved water safety management, as addressed by the Sustainable Development Goals, can be aided by Water Safety Planning, a risk-assessment and risk-management approach introduced by the World Health Organization and implemented to date in 93 countries around the globe. Yet, this approach still encounters some challenges in practice, including that of securing collaboration among the broad range of stakeholders involved. This paper presents a role-playing game designed to foster stakeholder collaboration in Water Safety Plans (WSP). In this role-play, participants take on different stakeholders' roles during a collective (team-based) decision-making process to improve water supply safety in a fictive town. The game is the result of a transdisciplinary initiative aimed at integrating knowledge across technical and governance aspects of WSPs into an active learning experience for water sector actors from diverse backgrounds. It exposes participants to the four phases of Kolb's experiential learning cycle: concrete experience, reflective observation, conceptualization and active experimentation. This paper discusses potential impacts of the WSP role-play, including skills and knowledge development among participants, which can support cross-sectoral integration and dealing with complexity in decision-making. These are capacity assets strongly needed to address water safety management challenges in a sustainable way.
\end{abstract}

Keywords: active learning; drinking water; role-play; stakeholder collaboration; Water Safety Plan; water supply

\section{Introduction}

The Sustainable Development Goals (SDGs) launched by the United Nations [1] aim at achieving, by 2030, "universal and equitable access to safe and affordable drinking water for all" (target 6.1). This poses a triple challenge: reaching unserved populations, improving existing service levels, and ensuring sustainability of existing and future services [2]. This target will be monitored by tracking the proportion of "safely managed drinking water services", which entails water that is free from contamination, available on premises and available when needed [3].

Water safety management may be aided by risk management approaches, such as Water Safety Plans (WSPs), a preventive risk assessment and management approach that encompasses all steps in water supply from catchment to consumers, including water treatment and distribution [4]. WSPs were originally introduced by the WHO in 2004 [5], following the 2001 Stockholm Framework [6] for the development of risk-based microbial water quality standards for all water uses. Since then, WSPs have been implemented in 93 countries around the world [7]. In the context of drinking water, WSPs require 
site-specific assessment of hazards impacting water quality from the watershed to the tap, and the identification and implementation of risk control measures, monitoring and management plans. Generally, the implementation of urban WSPs is led by the water supplier. Benefits related to WSP implementation include improved management and traceability, and a demonstrated reduction of the incidence of clinical cases of diarrhea [8].

Nevertheless, some challenges persist, such as securing executive buy-in (i.e., support from the top management), encountering a favorable organizational culture (i.e., a sense of collaboration towards a common goal of improved management practice and public health protection), and overcoming the perception of WSPs being an additional burden for utilities $[9,10]$. Further, one of the greatest challenges is to actively involve stakeholders other than the water supplier in the WSP process, despite the WSP manual reporting that favoring dialogue and collaboration among stakeholders is one of the benefits promoted by the WSP approach [11]. Improving water safety at the treatment and distribution stages may be manageable by the utility with limited commitment of other stakeholders, but a WSP cannot be fully implemented without the involvement of major stakeholders at catchment and at household scale. In fragmented water governance structures, cooperation among stakeholders in the implementation of WSPs, as encouraged by the Integrated Water Resources Management (IWRM) principles [12], generally doesn't occur.

Multiple approaches have been adopted for building capacities on WSP: these range from a variety of short courses (face-to-face or on-line) to Water Operators' Partnerships or courses at universities and higher education institutes. Most of the courses are based on teaching material developed by WHO \& IWA [13]. Nevertheless, after over 10 years of capacity building and the implementation of WSPs worldwide, research highlights that in many cases there is little evidence of involving stakeholders from the catchment in WSPs [14]. Hence, there is a need to support implementers with tools that facilitate or enhance collaboration between stakeholders. Additionally, Parker and Summerill [15] reported that the ability of WSPs to involve all stakeholders was seen as a motivation to engage in WSPs; yet, poor relationships with other stakeholders formed a barrier in several countries.

In this paper, we argue that role-plays can significantly contribute to both enhancing experience-based learning on governance of water safety management and developing skills required for water professionals dealing with the design and management of WSPs. Role-plays are a form of simulation in which learners engage actively in problem solving, while the teacher acts as facilitator and uses his/her knowledge to develop realistic scenarios, creating a 'situational interest' by presenting a problem stimulus [16]. They address the demand for active learning in multiple ways. First, pedagogical theories suggest that knowledge is not transferred from the teacher to the learner, but rather constructed by learners whilst the teacher acts as a facilitator $[17,18]$. This has important implications on the role of the learner, who ultimately holds the responsibility of his/her learning process $[19,20]$. Learning, therefore, requires actively engaging with the subject matter, as 'students learn best when they engage with course material and actively participate in their learning' [21-24], active learning techniques are increasingly being encouraged. Through the role-play, learners are exposed to a real-life situation in a protected environment that allows them to experience, experiment and repeat (trial and error), thus putting the learner in the condition of both constructing and enhancing their knowledge [25]. Participants take on an active role (e.g., a given stakeholder involved in water management) during the simulation of an activity that involves interacting and making decisions. In this process, activation is intrinsic: "individuals assume roles, act out their characters, experience the interaction and see the outcome" [20]. Second, the flexible structure of the role-play generally allows the pursuit of different scenarios and, in turn, multiple learning objectives. Because of the trial and error pattern, these also allow testing and reinforcing knowledge by practicing in a variety of scenarios [26]. Role-plays often entail multidisciplinary scenarios, in which different dimensions of a problem or a process are addressed in the controlled and safe environment of the role-play [25].

We present an original role-playing game developed to complement existing training materials with the following objectives: (i) raising awareness of water professionals of the added value of WSPs 
and ensuring a safe water supply globally, and thus of achieving Sustainable Development Goal 6, target 6.1 [3]; (ii) creating a learning environment where water professionals can practice stakeholder engagement while making strategic decisions on financial investments in the rehabilitation of a water supply system; (iii) demonstrating the importance of effective collaboration and integration among stakeholders in decision making on water supply safety. After presenting the game, we discuss the potential impact of the game on water professionals and on water governance at large.

\section{Materials and Methods}

The context of this role-playing game is a multiple-stakeholder decision-making process to address public health protection in relation to drinking water safety. Participants are divided into groups to experiment with decision making in two consecutive game rounds: (i) the first round simulates a 'fragmented' institutional environment, where stakeholders are segregated and communication is limited (ii) the WSP 'integrated' institutional environment is evaluated in the second round, when communication between stakeholders is intensified, eventually leading to a different outcome of the decision-making process. The outcome of both rounds is evaluated in terms of water quality risk reduction, revealing how stakeholder engagement and cooperation in the WSP decision-making process could lead to improved water quality through more efficient investment planning.

The target group includes water professionals of different backgrounds (i.e., public administration, engineers, policy makers) who may either implement or advocate for the implementation of WSP in the future. At a broader level, the game can also be used with other practitioners within the water sector (including - but not limited to-all stakeholders represented in this game), and as an educational tool for any group of students taking courses related to water governance and water services management.

The game was developed in 2016-2017 as a result of a collaboration between the Water Supply Engineering and Water Services Management chair groups at IHE Delft. This game is part of a set of tools developed by IHE Delft to support capacity building for water utilities in Water Operators' Partnerships towards achieving a range of performance goals. The game is the result of a transdisciplinary initiative aimed at integrating technical knowledge with water management and governance of WSPs into an active learning experience for water sector actors from diverse training backgrounds and fields.

The development of this game was an iterative process based on initial brainstorming and review of other serious gaming tools used in water management. The game was tested with (i) students enrolled in the Master Programme in Urban Water and Sanitation at IHE Delft ( $n=18)$, (ii) students enrolled in the Master Programme in Water Management at IHE Delft $(n=9)$, and (iii) researchers of the Dutch National Institute for Public Health and the Environment (RIVM) $(n=15)$. The game was part of a larger course or training on WSPs. Plenary feedforward sessions-that is, to listen to the suggestions for the future-were organized at the end of each game. The game developers listened to the suggestions, took notesk and integrated the suggested modifications into the subsequent revisions of the game. During the students' sessions, each team appointed a participant to take notes about potential improvements of the game. Additional guidance was sought from a WHO consultant experienced in WSP and role-play games. The game was finalized in August 2017 and is available open-access on the WSP Portal (http:/ / www.wsportal.org) of the IWA/WHO and on the BEWOP project website (http:/ / bewop.un-ihe.org). The final version of the game is intended to be played over a period of $4 \mathrm{~h}$, but includes additional features to turn it into a longer version (suggested $6 \mathrm{~h}$ ).

\section{Results}

In this section, the main features and stages of the game, i.e., the preparatory steps, round 1 and round 2 , and the outcomes of the testing process are described. 


\subsection{Preparatory Steps}

To begin with, the roles are assigned to participants and the case study is presented. The case study is a fictional town named BE, which is supplied with treated surface water. In BE town, agricultural activities in the catchment have significantly intensified over the past decades, moving from small-scale subsistence agriculture to larger-scale. A chemical factory has recently opened in the rural-urban fringe, and the quality of the river water has been drastically deteriorating. The water supply company is struggling to supply drinking water that meets basic water quality standards. In this scenario, the local government has received funds from a developing agency, which they must use to tackle multiple issues in the water and sanitation sector. In addition, the water company has its own budget to invest in rehabilitation. The total budget remains limited with respect to the range of issues faced by the utility, and therefore investment priorities need to be set.

Before diving into the game, participants are divided into teams, such that each team includes at least one participant representing each of the following stakeholders:

1. Catchment authority

2. Farmers' association

3. Industry

4. Water supply company

5. Local government

6. Ministry of Public Health

7. Consumers

\subsection{Round 1}

The first round of the game aims at allowing participants to experience a situation that is in many instances representative of typical real-life context, i.e., institutional fragmentation and limited communication among actors. The scenario of stakeholders' interconnections presented in Table 1 is given to participants, which use it to form the two sub-groups: one led by the local government (in grey in Table 1) and the other one led by the water supply company (in white in Table 1). Communication within the sub-groups is not allowed, and the information available to each sub-group differs, as detailed below.

Table 1. Stakeholders' interconnections and influence factors in decision making.

\begin{tabular}{|c|c|c|}
\hline Stakeholder & Links & $\begin{array}{l}\text { Influence } \\
\text { Factor }\end{array}$ \\
\hline Catchment authority & $\begin{array}{l}\text { Weak relationship with farmers' association about land use and agricultural practices } \\
\text { Weak relationship with industry about types of chemicals discharged in plant's } \\
\text { effluent } \\
\text { Weak (informative) relationship with city government as downstream user in the } \\
\text { catchment }\end{array}$ & $1 / 10$ \\
\hline Farmers' association & Weak relationship with catchment authority & $1 / 10$ \\
\hline Local government (municipality) * & Weak relationship with catchment authority & $6 / 10$ \\
\hline Water supply company * & $\begin{array}{l}\text { Relationship with customers based on billing, customer complaints and satisfaction } \\
\text { surveys } \\
\text { Weak relationship with Ministry of Public Health which provides guidance on } \\
\text { drinking water quality }\end{array}$ & $5 / 10$ \\
\hline Ministry of Public Health & Weak relationship with water supply company & $3 / 10$ \\
\hline
\end{tabular}

The water supply company has a budget of $1 \mathrm{M} B E \$$ and the local government of $3 \mathrm{M} B E \$$. Within each sub-group, stakeholders must discuss how to invest the money they have available over a period of 10 years, using the printed information available for each sub-group. Each stakeholder within the sub-group can influence investments of an amount corresponding to a fraction of the total 
budget managed by the local government or by the water supply company, based on the respective weight of each stakeholder. The amount is calculated as follows: amount of investment influenced by $\mathrm{X}=$ (influence factor) $\times$ (total budget sub-group). This relative influence of individual stakeholders with respect to collective investment decisions is referred to as the 'weight distribution' of stakeholders.

The sub-group led by the water supply company can use the WSP they recently developed (for the sake of the game, a summary of the WSP, focusing on the highest identified risks, is provided to the sub-group (i.e., it is assumed that this was developed by the water supply company through activities that are not part of the scope of the game)) (see an excerpt in Table 2), but they won't be able to invest on all the items listed in the improvement plan because of two reasons: (a) they have a limited budget, and (b) some interventions would require the collaboration of stakeholders from the other sub-group, with whom they cannot communicate (as exemplified in Table 2).

Table 2. Example of one high-risk hazard and possible control actions identified through the WSP.

\begin{tabular}{|c|c|c|c|c|c|c|c|}
\hline Hazard & Likelihood & Severity & Risk & Control Action & $\begin{array}{l}\text { Investment } \\
\text { (M BE\$) }\end{array}$ & $\begin{array}{c}\text { Risk after } \\
\text { Implementing the } \\
\text { Control Action }\end{array}$ & $\begin{array}{c}\text { Stakeholders } \\
\text { Involved/Remarks }\end{array}$ \\
\hline \multirow{2}{*}{$\begin{array}{l}\text { Pesticides } \\
\text { from } \\
\text { agricultural } \\
\text { uses }\end{array}$} & \multirow{2}{*}{4} & \multirow{2}{*}{3} & \multirow{2}{*}{12} & $\begin{array}{l}\text { 1.A-Improved farmers' } \\
\text { practices involving a } \\
\text { reduced use of pesticides }\end{array}$ & 0.8 & 9 & $\begin{array}{l}\text { Requires close } \\
\text { collaboration with } \\
\text { farmers and } \\
\text { coordination through } \\
\text { the catchment authority }\end{array}$ \\
\hline & & & & $\begin{array}{l}\text { 1.C-Improved treatment } \\
\text { at the drinking water } \\
\text { treatment plant through } \\
\text { punctual dosing of } \\
\text { powdered activated } \\
\text { carbon during and after } \\
\text { intense rainfall events }\end{array}$ & 1.2 & 6 & $\begin{array}{l}\text { Requires close } \\
\text { collaboration with } \\
\text { catchment authority for } \\
\text { accurate and timely } \\
\text { information on rainfall } \\
\text { events }\end{array}$ \\
\hline
\end{tabular}

Meanwhile, the sub-group led by the local government can only rely on a list of various issues that have been raised over the past few years of the government's mandate around water supply and water management, along with the estimated funding required to address the issue at the time it was raised. This sub-group therefore does not have access to the information contained in the WSP. The two sub-groups will eventually deliver different investment plans and it will become evident that both the presence of a WSP and stakeholders' collaboration could considerably improve the decisions to be taken.

\subsection{Round 2}

In this second round, stakeholders play as one group (i.e., both sub-groups are reunited into the original team). In addition, they have the opportunity to re-define the interconnections and the influence factor of each stakeholder. Participants reflect on what the consequences and limitations of such a weight distribution are, and how it can be reconsidered and improved in order to increase the benefits of coordinated decision-making on water supply.

The spending of the total budget (4M BE\$ in total) is guided by an investment plan based on the prioritization of risks and control measures as informed by the WSP. The stakeholders can negotiate which investment they support, based on their own interest. If a given option requires collaboration from specific stakeholders, these stakeholders must agree to support at least part of the investment required to implement that control action. During the discussion, play-money can be placed on a chart that illustrates all possible investment decisions and their respective costs (Figure 1). 


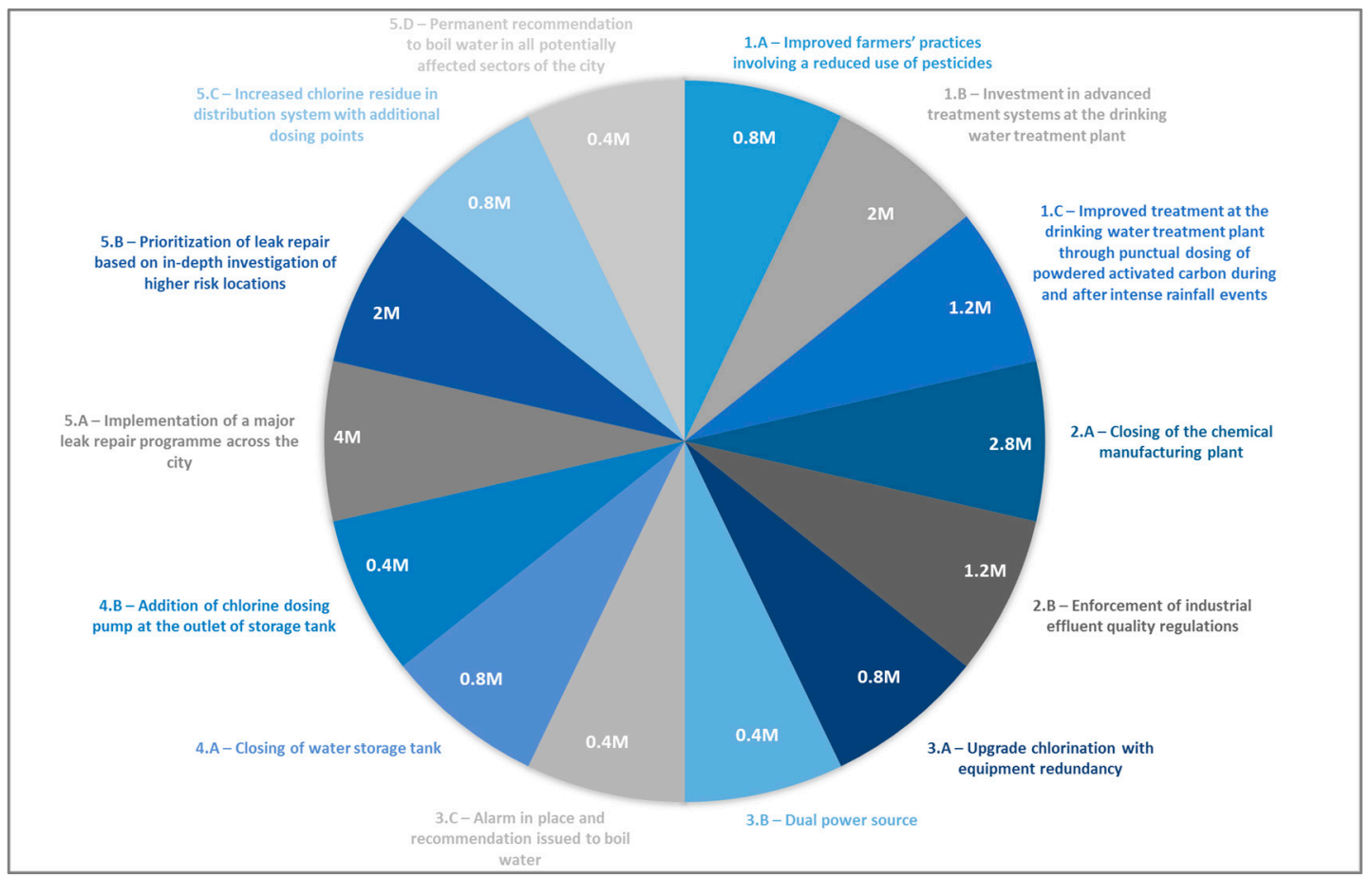

Figure 1. Chart used to illustrate investment decisions made by a team in round 2.

Stakeholders should aim at the set of investments that will result in the greatest risk reduction.

When playing in a large group with several teams, and/or if there is more time available for playing the game $(\sim 5-6 \mathrm{~h})$, the trainer can distribute 'unexpected event cards', which include natural calamities that restrict the budget available or new risks that need to be immediately tackled, thereby influencing priorities and the set of investment decisions that the team settles on during this second round.

\subsection{Feedback Session}

The game ends with a discussion on various aspects of the game, particularly comparing the outcomes of the two rounds of the game. Additionally, the connections between stakeholders and their respective influence factor are discussed, as well as the rationale, interactions and processes behind the group's decisions on investment. Finally, participants are guided through assessing the 'take home' message from playing this game:

- Could participants relate the experience of stakeholders' fragmentation in the game's first round to the water supply sector situation in their own country?

- Could participants appreciate the value of the WSP as a support tool to protect public health in water provisioning?

- Could participants appreciate the value of stakeholders' collaboration while taking strategic decisions on investments during the second round?

\subsection{Testing Process}

A total of 27 Master students and 15 public health practitioners and researchers tested the game. Only 4 participants $(15 \%)$ among the students group and 3 participants $(20 \%)$ among the public health practitioners and researchers group had previous experience with WSP. Master students stated that they could clearly relate the stakeholders' fragmentation to the water sector in their own country, being mainly from developing and in-transition countries, but this was more difficult for the public health practitioners and researchers from The Netherlands. Moreover, the trainers observed that the 
group of Master students was easily acting out the roles throughout the game, whereas the group of public health practitioners and researchers had more difficulties in adhering to their roles.

Participants in both IHE student groups were asked to discuss their experience orally after playing the game. All participants in the student groups mentioned that, through the game, they gained a better understanding about the importance of stakeholders' engagement for the successful implementation of WSP. Many participants in the student group also mentioned that they would be likely to play this game in the future, to support training on WSP and stakeholder coordination on water management from catchment to tap. These last two points were not discussed with the public health practitioner and researcher groups. The latter was requested to fill in a simple evaluation form that included one question related to each part of a broader training workshop of which the game was part. Only partial results were obtained from this group: 7 out 15 participants filled in the evaluation; 5 out of 7 were extremely positive about the game and 2 out of 7 were neutral.

Another extremely important component of the testing process was the feedforward session. The main suggestions received from participants were related to the operationalization of the game. This included, for instance, adding a "fun element" to the game. As a result, the team developed play-money to be placed on a chart that illustrates all possible investment decisions (Figure 1). Additionally, Master students helped the trainers to improve the process for allocating money to each stakeholder by simplifying the influence factor approach (Table 1). Other suggestions included elucidating some minor clarity issues in the participant's and trainer's guidance manuals, which were addressed in the final version available online.

Finally, expert opinion on the game was sought from a WHO consultant who had extensive experience with role-playing games in relation to water safety. His most valuable suggestion was to let participants reflect on the risk minimization linked to each control action, in order to overcome the tendency to focus just on cost (Figure 1). His suggestions also enabled the improvement of operational elements of the game, such as color coding of stakeholders' tags, and adding guidance in the trainer's manual on how to organize the room and facilitate the role-play the when playing the game with larger or smaller groups.

\section{Discussion and Conclusions}

This section discusses the potential impact of the WSP role-play on knowledge and skills development among participants, as well as the potential impact on longer-term water quality planning and management. First, the game offers the opportunity to experience the importance of integrated approaches to water quality management. It is often argued that the so-called "water crisis" is, to a large extent, "a crisis of governance" [27-29]. Water governance is complex and involves a wide range of interconnected processes, embedded in fragmented and institutionally complex systems [30,31]. Managing water quality from catchment to tap and protection of public health require understanding water challenges as interconnected at the city, region or basin scale, as well as among users and across the water cycle. In experiencing the different scenarios (without and with collaboration of different stakeholders), participants become aware of the crucial need for stakeholder collaboration to achieve safe water supply.

Further, water quality management, just as suggested by IWRM principles [12], entails developing a set of skills and competencies for water professionals to deal with integration and complexity [25]. In fact, professionals in the water sector are increasingly required to have an in-depth knowledge in their specific field, whilst being well versed in adjacent and related ones [32]. Implementing WSPs requires not only an expertise on water quality and supply operations, but also an understanding of water governance processes and negotiation skills, such as dealing with allocation of resources or the right to pollute entails developing collaborations and handling potential conflicts [25,33,34]. During the game, participants are exposed to two different types of negotiations, where they must agree on budget allocations, establish priorities and reach an agreement with stakeholders that might have different positions and interests. The long version of the game also simulates unexpected events 
such as a sewage pipe break, unforeseen operational problems at the water treatment plant, new regulatory requirements for water quality, farmers going on strike, extreme weather conditions, etc. This scenario-based training forces participants to engage in new and more complex negotiations, and to think about how to address the event and return to business as usual or reach adapted, acceptable (or even improved) operational conditions. It exposes the participants to the reality of unexpected, dynamic, evolving conditions, and therefore increases their awareness to the context of uncertainty in decision-making processes. Moreover, understanding and addressing water governance challenges, which constitute one of the bottlenecks in effective water safety management, require interdisciplinary analyses encompassing both the institutional (i.e., socio-political, cultural, ethical and legal) and the technical dimensions (e.g., geo-hydrological and engineering assessments, water quality monitoring) of water management $[35,36]$. By simulating a real decision-making context involving multiple stakeholders, this game allows participants to experience some of these various dimensions of water management, as conflicting interests and priorities of the different stakeholders will emerge from the teams' discussion and decision processes.

Moreover, this role-play represents an important tool for enhancing participants' knowledge on water safety management from catchment to tap, i.e., the WSP approach, including associated challenges and benefits, and on the impact of various stakeholders on water supply safety. Participants build this knowledge through active problem solving by making decisions on investments on water safety and by conciliating different stakeholders' interests (especially at the second round). In fact, role-playing games have the potential to be especially effective when the desired performance objective of the training involves problem solving [16].

According to Kolb, experience plays into the learning process [37]. The game exposes participants to different learning moments that cater to different learning styles. At different points in the game, participants are exposed to the four stages of Kolb's experiential learning cycle (Figure 2). In the first round of the role-play exposes students to what Kolb defines a Concrete Experience (1): here, participants experience the behavior, different levels of influence and potentially conflicting interests of stakeholders involved or affected by water safety management. They experience this in a simulated 'fragmented' system, representative of real-life context in many instances. The concrete experience leads to Reflective Observation (2): before starting the second round, participants in both sub-groups reflect on the outcome of the first round and on the challenges they faced. Through the plenary feedback discussion, some level of Conceptualization (3) can be derived from the previous stages, e.g., on WSPs as tools for strengthening the decision-making process on water safety investment and on the need for stakeholders' collaboration. This stage also works as a tool for facilitators to test participants' knowledge on water safety management from catchment to tap. In this phase they identify and describe the challenges faced in the implementation of WSP and the impact of various stakeholders on water supply safety. Finally, by playing the second round of the game, participants can engage in Active Experimentation (4): they practice the concepts they have just approached through another round of role-play, in a simulated 'integrated' system, with the potential to further practice later in real-life situations as water professionals.

As a result, the game has the potential to provide both short-term impacts (e.g., achieving the learning objectives during the training) and medium-term impacts (real-life WSP implementation). Beyond this, the set of skills and the type of knowledge that the game seeks to develop among water professionals aspires to longer-term, broader impact on transformative change: skills and knowledge that help support cross-sectoral integration and deal with complexity in decision-making are increasingly needed in order to address sustainability challenges. The active learning material presented in this study aims at contributing towards a better understanding of the WSP approach, as a tool for water utilities to engage with a broader network of stakeholders, but also to further challenge-based training of water professionals on social and interactional skills' development, which are critical to solve the pressing issues underpinned by the SDGs. 


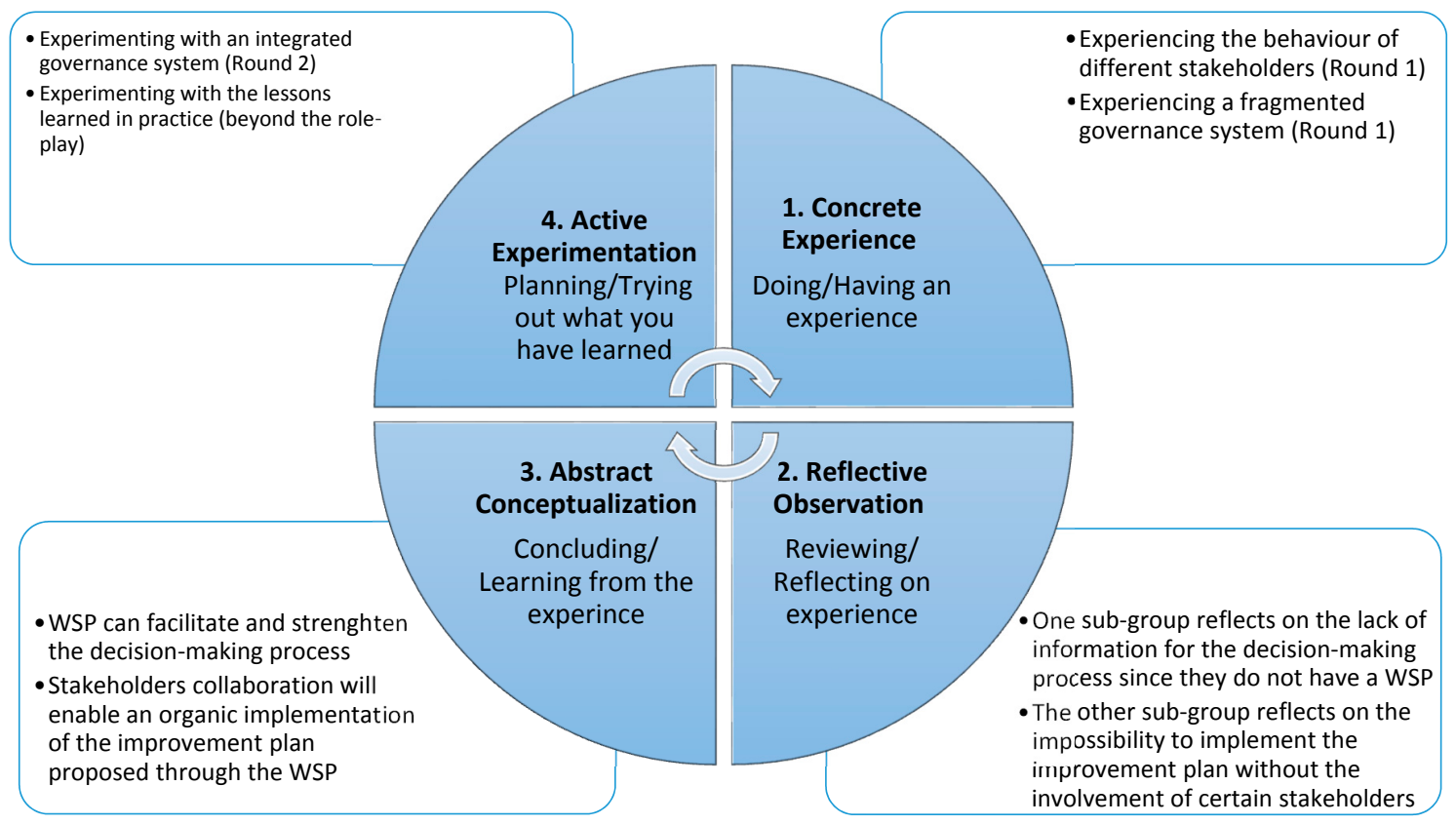

Figure 2. Kolb's experiential learning cycle stages through the WSP role-play.

Acknowledgments: The game has been developed within the framework of the project "Boosting the efficiency of Water Operators Partnerships (BEWOP)", sponsored by the Dutch Government (DGIS).

Author Contributions: Françoise Bichai and Giuliana Ferrero developed the game. Giuliana Ferrero tested the game. Darryl Jackson reviewed the game. Giuliana Ferrero, Françoise Bichai and Maria Rusca wrote the paper.

Conflicts of Interest: The authors declare no conflict of interest. The founding sponsors had no role in the design of the study, in the writing of the manuscript, and in the decision to publish the results.

\section{References}

1. UN. Transforming Our World: The 2030 Agenda for Sustainable Development. Resolution Adopted by the General Assembly on 25 September 2015, A/70/1. Available online: http:/ /www.un.org/en/development/ desa/population/migration/generalassembly/docs/globalcompact/A_RES_70_1_E.pdf (accessed on 3 December 2017).

2. World Bank. Sustainability Assessment of Rural Water Service Delivery Models: Findings of a Multi-Country Review; World Bank: Washington, DC, USA, 2017; Volume 8. Available online: https:/ / openknowledge.worldbank. org/bitstream/handle/10986/27988/W17055.pdf?sequence=4\&isAllowed=y (accessed on 3 December 2017).

3. World Health Organization (WHO). Safely Managed Drinking Water-Thematic Report on Drinking Water 2017; World Health Organization: Geneva, Switzerland, 2017; ISBN 9789241565424.

4. World Health Organization (WHO). Guidelines for Drinking-Water Quality, 4th ed.; World Health Organization: Geneva, Switzerland, 2011; ISBN 9789241548151.

5. World Health Organization (WHO). Guidelines for Drinking-Water Quality, 3rd ed.; World Health Organization: Geneva, Switzerland, 2004; ISBN 9241546387.

6. Fewtrell, L.; Bartram, J. Water Quality: Guidelines, Standards and Health: Assessment of Risk and Risk Management for Water-Related Infectious Diseases; World Health Organization: Geneva, Switzerland, 2001; ISBN 924154533X.

7. World Health Organization (WHO). Global Status Report on Water Safety Plans: A Review of Proactive Risk Assessment and Risk Management Practices to Ensure the Safety of Drinking-Water; World Health Organization: Geneva, Switzerland, 2017; Licence: CC BY-NC-SA 3.0 IGO. 
8. Gunnarsdottir, M.J.; Gardarsson, S.M.; Elliott, M.; Sigmundsdottir, G.; Bartram, J. Benefits of water safety plans: Microbiology, compliance, and public health. Environ. Sci. Technol. 2012, 46, 7782-7789. [CrossRef] [PubMed]

9. Summerill, C.; Pollard, S.J.T.; Smith, J.A.; Breach, B.; Williams, T. Securing executive buy-in for preventative risk management-Lessons from water safety plans. Water Sci. Technol. Water Supply 2011, 11, 682-691. [CrossRef]

10. Kot, M.; Castleden, H.; Graham, A.; Gagnon, G.A. The human dimension of water safety plans: A critical review of literature and information gaps. Environ. Rev. 2015, 23, 24-29. [CrossRef]

11. Bartram, J.; Corrales, L.; Davison, A.; Deere, D.; Drury, D.; Gordon, B.; Howard, G.; Rinehold, A.; Stevens, M. Water Safety Plan Manual: Step-By-Step Risk Management for Drinking-Water Suppliers; World Health Organization: Geneva, Switzerland, 2009; ISBN 9789241562638.

12. Global Water Partnership (GWP). Integrated Water Resources Management; Global Water Partnership (GWP) Technical Advisory Committee: Stockholm, Sweden, 2000; Background Paper No.4; ISSN 1403-5324.

13. WSP Training Package. Available online: http://www.who.int/water_sanitation_health/publications/wsp_ training_package/en/ (accessed on 12 December 2017).

14. Omar, Y.Y.; Parker, A.; Smith, J.A.; Pollard, S.J.T. Risk management for drinking water safety in low and middle income countries-Cultural influences on water safety plan (WSP) implementation in urban water utilities. Sci. Total Environ. 2017, 576, 895-906. [CrossRef] [PubMed]

15. Parker, A.; Summerill, C. Water safety plan implementation in East Africa: Motivations and barriers. Waterlines 2013, 32, 113-124. [CrossRef]

16. Rotgans, J.I.; Schmidt, H.G. Situational interest and academic achievement in the active-learning classroom. Learn. Instr. 2011, 21, 58-67. [CrossRef]

17. Boekaerts, M.; Pintrich, P.R.; Zeidner, M. Self-Regulation: Theory, Research, and Applications. In Handbook of Self-Regulation; Academic Press: Orlando, FL, USA, 2000; ISBN 9780121098902.

18. Niemi, H. Active learning-A cultural change needed in teacher education and schools. Teach. Teach. Educ. 2002, 18, 763-780. [CrossRef]

19. Biggs, J.B.; Tang, C. Teaching for Quality Learning at University; Open University Press, McGraw-Hill Education: Maidenhead, UK, 2007.

20. Oblinger, D. The next generation of educational engagement. J. Interact. Media Educ. 2004, 8, 1-18. [CrossRef]

21. Jonassen, D.H.; Rohrer-Murphy, L. Activity theory as a framework for designing constructivist learning environment. Educ. Technol. Res. Dev. 1999, 47, 61-79. [CrossRef]

22. The Manager's Core Work in the New Economy. Available online: http://www.newmango.com/01iftf/ henschel.html (accessed on 12 December 2017).

23. Dale, E. Audiovisual Methods in Teaching, 3rd ed.; The Dryden Press: New York, NY, USA, 1969.

24. Freeman, S.; Eddy, S.L.; McDonough, M.; Smith, M.K.; Okoroafor, N.; Jordt, H.; Wenderoth, M.P. Active learning increases student performance in science, engineering, and mathematics. PNAS 2014, 111, 8410-8415. [CrossRef] [PubMed]

25. Rusca, M.; Heun, J.; Schwartz, K. Water management simulation games and the construction of knowledge. Hydrol. Earth Syst. Sci. 2012, 16, 2749-2757. [CrossRef]

26. Ruben, B.D. Simulations, games, and experience-based learning: The quest for a new paradigm for teaching and learning. Simul. Gaming 1999, 30, 498-505. [CrossRef]

27. UNESCO. Water, a Shared Responsibility; The United Nations World Water Report 2, UNESCO and Berghahn Books; UN-HABITAT: Paris, France; New York, NY, USA, 2006; ISBN 9231040065.

28. Lautze, J. (Ed.) Key Concepts in Water Resource Management: A Review and Critical Evaluation; Routledge-Earthscan: New York, NY, USA, 2014; ISBN 9780415711739.

29. Castro, J. Water governance in the twenty-first century. Ambient. Soc. 2007, 10, 97-118. [CrossRef]

30. Lubell, M.; Robins, G.; Wang, P. Network structure and institutional complexity in an ecology of water management games. Ecol. Soc. 2014, 19, 23. [CrossRef]

31. Pahl-Wostl, C.; Holtz, G.; Kastens, B.; Knieper, C. Analyzing complex water governance regimes: The Management and Transition Framework. Environ. Sci. Policy 2010, 13, 571-581. [CrossRef]

32. Oskam, I.F. T-shaped engineers for interdisciplinary innovation: An attractive perspective for young people as well as a must for innovative organisations. In Proceedings of the 37th Annual Conference-Attracting students in Engineering, 1-4 July 2009. 
33. Douven, W.; Mul, M.L.; Alvarez, B.F.; Son, L.H.; Bakker, N.; Radosevich, G.; van der Zaag, P. Enhancing capacities of riparian professionals to address and resolve transboundary issues in international river basins: Experiences from the Lower Mekong River Basin. Hydrol. Earth Syst. Sci. Discuss. 2012, 9, 3813-3849. [CrossRef]

34. Seibert, J.; Vis, M.J.P. Irrigania-A web-based game about sharing water resources. Hydrol. Earth Syst. Sci. 2012, 16, 2523-2530. [CrossRef]

35. Rusca, M.; Boakye-Ansah, A.S.; Loftus, A.; Ferrero, G.; van der Zaag, P. An interdisciplinary political ecology of drinking water quality. Exploring socio-ecological inequalities in Lilongwe's water supply network. Geoforum 2017, 84, 138-146. [CrossRef]

36. Zwarteveen, M.; Kemerink-Seyoum, J.S.; Kooy, M.; Evers, J.; Acevedo Guerrero, T.; Batubara, B.; Biza, A.; Boakye-Ansah, A.; Faber, S.; Cabrera Flamini, A.; et al. Engaging with the politics of water governance. WIREs Water 2017, 4, 1-9. [CrossRef]

37. Kolb, D.A. Experiential Learning: Experience as the Source of Learning and Development; Prentice Hall: Englewood Cliffs, NJ, USA, 1984.

(c) 2018 by the authors. Licensee MDPI, Basel, Switzerland. This article is an open access article distributed under the terms and conditions of the Creative Commons Attribution (CC BY) license (http:/ / creativecommons.org/licenses/by/4.0/). 